\title{
Ultrasonographical examination of bovine claws through the sole horn on weight-bearing claws
}

\author{
K. Bach, ${ }^{1 *}$ S. S. Nielsen, ${ }^{2}$ A. M. Danscher, ${ }^{3}$ and N. Capion ${ }^{1}$ \\ ${ }^{1}$ Department of Veterinary Clinical Sciences, University of Copenhagen, Dyrlægevej 16, 1870 Frederiksberg C, Denmark \\ ${ }^{2}$ Department of Veterinary and Animal Sciences, University of Copenhagen, Grønnegårdsvej 15, 1870 Frederiksberg C, Denmark \\ ${ }^{3}$ Boehringer Ingelheim Animal Health, Strødamvej 52, 2100 København Ø, Denmark
}

\section{ABSTRACT}

Claw horn disruptions in the bovine claw are believed to be a consequence of pressure on the sole corium from the third phalanx, which may be caused by a weakening of the suspensory apparatus in the claw. We aimed to develop an ultrasonographic method that would make it possible to measure the thickness of the soft tissue between the third phalanx and the sole horn on a weightbearing claw. A device was developed to record the sole horn and soft tissue thickness indirectly through a polyethylene plate, and 52 feet from slaughtered cows were examined using ultrasonography, both directly and indirectly. Soft tissue and sole horn thickness measurements in the apex and the plantar part of the sole were compared with anatomical measurements of transected claws. To assess the method on weight-bearing versus non-weight-bearing claws, we examined the hind claws of 10 live cattle without transection. We found a weak correlation between the soft tissue thickness measured by ultrasound and anatomical measurements. A strong correlation was observed between the direct ultrasound approach and the developed indirect method. There was a considerable difference between weight-bearing and non-weight-bearing claws, signifying a weak or nonexistent correlation. However, this part of the study was only done on 10 live cows and the results should be interpreted with caution. We concluded that it would be possible to measure the soft tissue using an indirect ultrasound approach on a weight-bearing-claw standing on a polyethylene plate. The major difference between the results of weight-bearing versus non-weight-bearing claws suggests that future studies of the suspensory apparatus could focus on weight-bearing claws.

Key words: dairy cow, claw horn, digital cushion, ultrasound

Received March 23, 2018.

Accepted January 6, 2019.

*Corresponding author: kurtbach@sund.ku.dk

\section{INTRODUCTION}

Claw horn disruption lesions can lead to lameness that compromises the welfare of the cow (Klaas et al., 2003) and result in decreased productivity, increased treatment costs, and early culling. This can represent a substantial economic loss to the dairy farmer (Bicalho et al., 2007; Ettema et al., 2007; Bruijnis et al., 2010).

The mechanism behind the development of claw horn disruption lesions is not fully understood. However, Lischer et al. (2002) showed that the soft tissue between the third phalanx and the sole horn was significantly thinner on claws with a sole ulcer than on normal healthy claws. Their study used anatomical measurements on dissected claws from slaughtered cows with and without sole ulcers. The authors suggested that weakening of the suspensory apparatus and a subsequent downward displacement of the third phalanx within the claw capsule could be one explanation for the development of lesions. This displacement could lead to compression and possible damage to the hornproducing tissue beneath the third phalanx, thereby causing sole hemorrhage and other claw horn disruption lesions.

By assessing the biomechanical properties of hoof wall segments from heifers euthanized in different weeks from parturition, Tarlton et al. (2002) showed that the suspensory apparatus was weakened around the time of calving and hypothesized that this could lead to a sinking or rotation of the third phalanx. However, to our knowledge, this hypothesis has not been investigated in live cows or weight-bearing legs.

Ultrasonography has been described as a valid method to image the sole horn and the internal structures of the claw. Kofler et al. (1999) compared measurements from B-mode ultrasonographic images with anatomical measurements taken from claws from the slaughterhouse, finding a strong correlation $(\mathrm{r} \geq 0.88)$ between measurements of the sole horn, and moderate correlation $(\mathrm{r} \geq 0.51)$ for soft tissue measurements. Laven et al. (2010) found a strong correlation $(r \geq 0.85)$ between ultrasound and anatomical measurements of the distance 
from the external sole surface to the third phalanx, and a moderate correlation $(\mathrm{r}=0.53)$ when measuring the thickness of the sole horn, mainly due to the challenges involved in identifying the internal margin of the sole horn on several of the claws.

Measurements of the sole horn and subsolar soft tissue thickness were successfully carried out on live animals using ultrasound on lifted feet after trimming (van Amstel et al., 2003, 2004). This method has further been used to describe the thickness of the digital cushion in relation to BCS on dairy cows in different stages of the lactation (Bicalho et al., 2009; Newsome et al., 2017). These studies demonstrated that a cow with low BCS had a thinner digital cushion and a greater risk of being lame compared with cows having higher BCS.

We aimed to develop a noninvasive method based on ultrasonography that would make it possible to measure the thickness of the soft tissue between the third phalanx and the internal margin of the sole horn on a weight-bearing claw. Specifically, it was our objective to assess the correlation between soft tissue and sole thickness measured by 3 different methods in different areas of the sole horn from slaughterhouse feet. The methods compared were direct ultrasonography through the sole horn, indirect ultrasonography through a polyethylene plate, and anatomical measurements made on a transected claw. As a part of the study it was our objective to assess the precision of the 2 ultrasonographic methods. A secondary objective was to assess if the method used on slaughterhouse feet could be used on a smaller number of live cows, comparing weight-bearing claws with non-weight-bearing claws.

It was our hypothesis that there would be no difference in measurements made on slaughterhouse feet using the 3 different methods and we expected that the method could be used on live cows.

\section{MATERIALS AND METHODS}

\section{Device for Ultrasonographic Measurements}

A method inspired by techniques used in human biomechanical studies (Matteoli, 2011) was developed, in which the claw was placed on a polyethylene plate and the ultrasonographic examination was performed indirectly from below. It was important that the images from the examination were of sufficient quality to allow for identification of different structures inside the claw. Specifically, it should be possible to measure the distance between the outer and inner margin of the sole horn and tuberculum flexorum and apex of the third phalanx. In collaboration with a company that specialize in plastic products (RIAS, Roskilde, Denmark), we designed and produced a tub made of white polyeth- ylene. The dimensions are shown in Figure 3. The tub was cut from a single 60 -mm-thick polyethylene plate, leaving the bottom of the tub $10 \mathrm{~mm}$ thick. Polyethylene was chosen for its strength and its acoustic properties, which are similar to that of water (Hendee and Ritenour, 2003).

\section{Sampling and Preparation of Feet}

To address the second objective, 52 hind feet from 52 different Holstein cows were collected from a slaughterhouse. The feet were collected by convenience sampling, and apart from making sure that they originated from Holstein cows, no other information was known about the animals. After sampling, the feet were washed with water and stored at $6^{\circ} \mathrm{C}$ until the following day. The sole horn was trimmed by the Danish method (Fritzbøger and Smedegaard, 1962) using an electric angle grinder. The basic steps in the Danish method are as follows:

- Starting on the largest claw (generally, but not always, the lateral hind claw and the medial front claw), it is sought to trim the toe angle to approximately 45 to $50^{\circ}$, while leaving a sole thickness of 8 to $10 \mathrm{~mm}$.

- Second, the small claw is trimmed to fit the large claw in heel height and toe angle if possible, which means the toe angle and the sole are trimmed to the same level as the large claw.

- When the sole horn on the 2 claws is leveled out as much as possible, both soles are modeled with a 3- to 4-mm-deep slope. It should cover the area from the midline of the claw to the interdigital space and from the palmar/plantar part of axial wall to the heel bulb.

When trimming the claws, the sole was not modeled to ensure maximum contact between the sole horn and the ultrasound transducer. Only claws free of lesions were used. After trimming, the feet were covered from the proximal part of the metatarsus to the fetlock joint with a rectal examination glove to ensure blinding.

Ultrasonographic examination was performed approximately $24 \mathrm{~h}$ after slaughter and carried out using a GE Logiq e portable scanner (Chicago, IL) equipped with a $14 \times 48 \mathrm{~mm}$ GE i739L-RS linear transducer with bandwidth of 3.5 to $10.0 \mathrm{MHz}$. The examination was performed in $\mathrm{B}$-mode at $6 \mathrm{MHz}$, with medium gain at a depth of $4.0 \mathrm{~cm}$.

\section{Direct Ultrasonography}

Ultrasonography directly through the sole horn was performed as described by Kofler et al. (1999). 


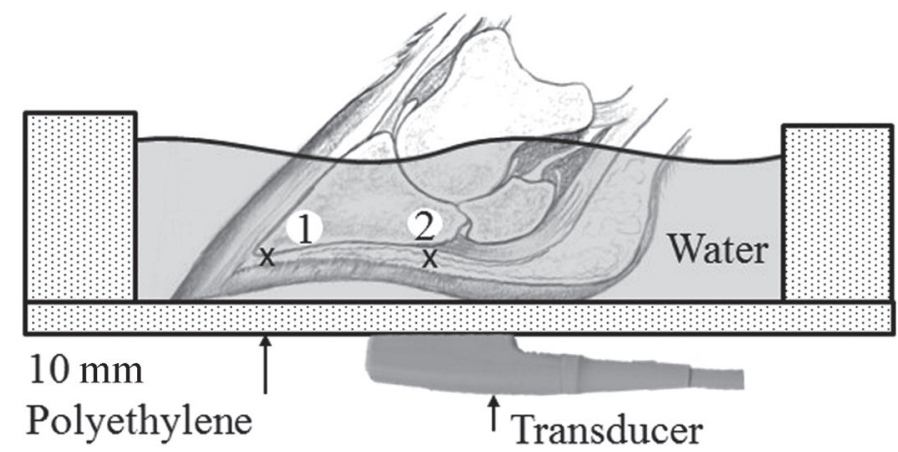

Figure 1. Indirect scanning performed through the polyethylene plate. The claw was placed in water to avoid any air getting between the bottom of the tub and the sole horn. The $2 \mathrm{X}$ marks indicate site 1 at the apex of the claw and site 2 in the plantar part of the sole where the measurements were taken.

An ample amount of coupling gel was applied to the transducer before it was placed directly in the midline of the toe area of the sole horn, visualizing the apex of the third phalanx (site 1; Figure 1). In the plantar part of the sole (site 2; Figure 1), the transducer was placed in the midline between the abaxial grove and the axial border. On the image, the internal margin of the sole horn and the third phalanx was located, and the tuberculum flexorum of the third phalanx was then identified. The transducer was slightly tilted from side to side to identify the site of the shortest distance between the third phalanx and the sole horn. The picture was then frozen and saved on the scanner's hard drive for subsequent evaluation. The same procedure was followed at site 1 . An image from a direct scan at site 2 is displayed on the left in Figure 2. We did not distinguish between lateral and medial claws.

When 10 claws had been examined, the order of the feet was randomized, and examinations were repeated so that each claw and site was examined 3 times. After the third exam, we used an electric wood-burning pen to mark the sites where scanning was performed. The marks functioned as aiming points for the later transection.

\section{Indirect Ultrasonography}

Claws were placed in the custom-made tub with the sole surface of the claw resting on the bottom. The tub was filled with $5 \mathrm{~cm}$ of water to prevent any air between the sole horn and the bottom of the tub. The ultrasound transducer was placed under the tub, and scanning was performed though the polyethylene and the sole horn (Figure 1). Plenty of ultrasound gel was used to maximize contact with the polyethylene plate.

Scanning was repeated as described under direct ultrasonography, with 3 replicate measurements taken at 2 sites per claw, and with randomization of the order of the feet between the examinations. An indirect ultrasonography image is displayed on the right in Figure 2.

The thickness of the sole and the distance between the inner margin of the sole horn and the third phalanx were measured on the recorded images using the

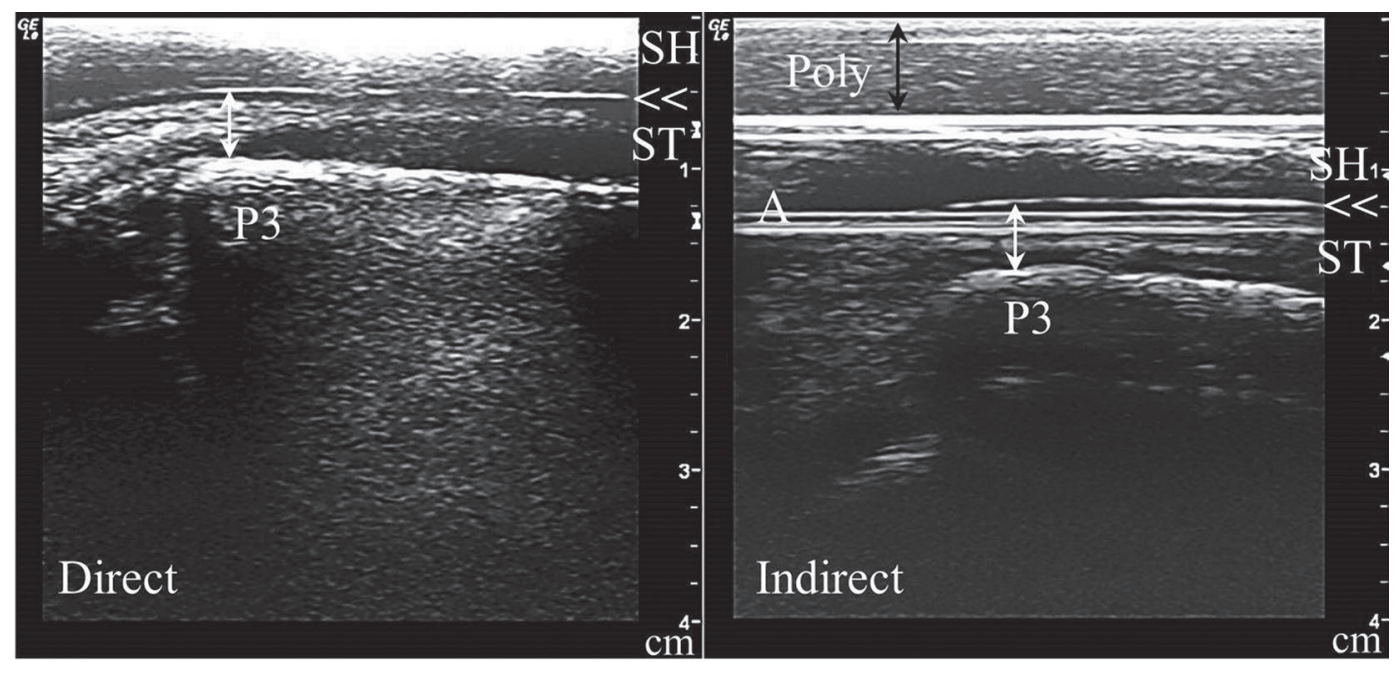

Figure 2. Two images of scanning at site 2. On the left: scanning directly through the sole horn (direct). On the right: scanning through the polyethylene plate (indirect). From the top, the different structures are sole horn (SH), sole horn/corium border $(\ll)$, soft tissue (ST), and the third phalanx (P3). The polyethylene tub (Poly) can be seen on the right-hand image, shown by a black double arrow ( $\uparrow$ ). The white double arrow $(\uparrow)$ on both images shows the soft tissue measured. The horizontal lines (A) on the indirect scan are artifacts from reflections of the polyethylene plate. The scale to the right in each image is in centimeters. 
measuring software of the scanner. The measurements were taken in millimeters with a precision of $0.1 \mathrm{~mm}$. All ultrasound examinations were performed within 48 $\mathrm{h}$ of postmortem.

\section{Anatomical Measurements}

After the last ultrasonography, the claws were stored at $-20^{\circ} \mathrm{C}$ for $48 \mathrm{~h}$. While frozen, each claw was cut along the transverse plane through the burn marks using a band saw. The thickness of the sole and the distance between the inner margin of the sole horn and the third phalanx were measured in millimeters with a precision of $0.1 \mathrm{~mm}$ at each site using a Mitsutomo digital sliding caliper (Yongjing, Taiwan).

\section{Assessment in Live Cows}

The polyethylene tub was built into a plywood platform covered in rubber (Figure 3), elevated $10 \mathrm{~cm}$ from the floor by wooden planks, and placed in the bottom of a stand-up trimming chute (KVK, Esbjerg, Denmark).
This allowed the cows to be held (in a headlock) with both hind feet in the tub and the transducer introduced underneath the tub during scanning.

Ultrasonography was performed on 10 Holstein cows (animals from the Large Animal Teaching Hospital at the University of Copenhagen), which were placed on the platform as described. The hind claws were placed in the tub and covered with $5 \mathrm{~cm}$ of water, and each claw was examined at 2 sites as previously described, using indirect ultrasonography (Figure 1). When the shortest distance between the sole horn and the third phalanx was identified, a video loop of the last $10 \mathrm{~s}$ of examination was saved on the hard drive of the GE Logiq e for evaluation. Weight-bearing was assessed visually during examination to ensure equal weightbearing on both hind legs. The construction of the platform did not allow examination of the front claws.

After examining the weight-bearing claws, the platform was removed and the examination was repeated on the same cows, this time held in the chute. The hind legs were lifted, and examination was done directly through the sole horn.

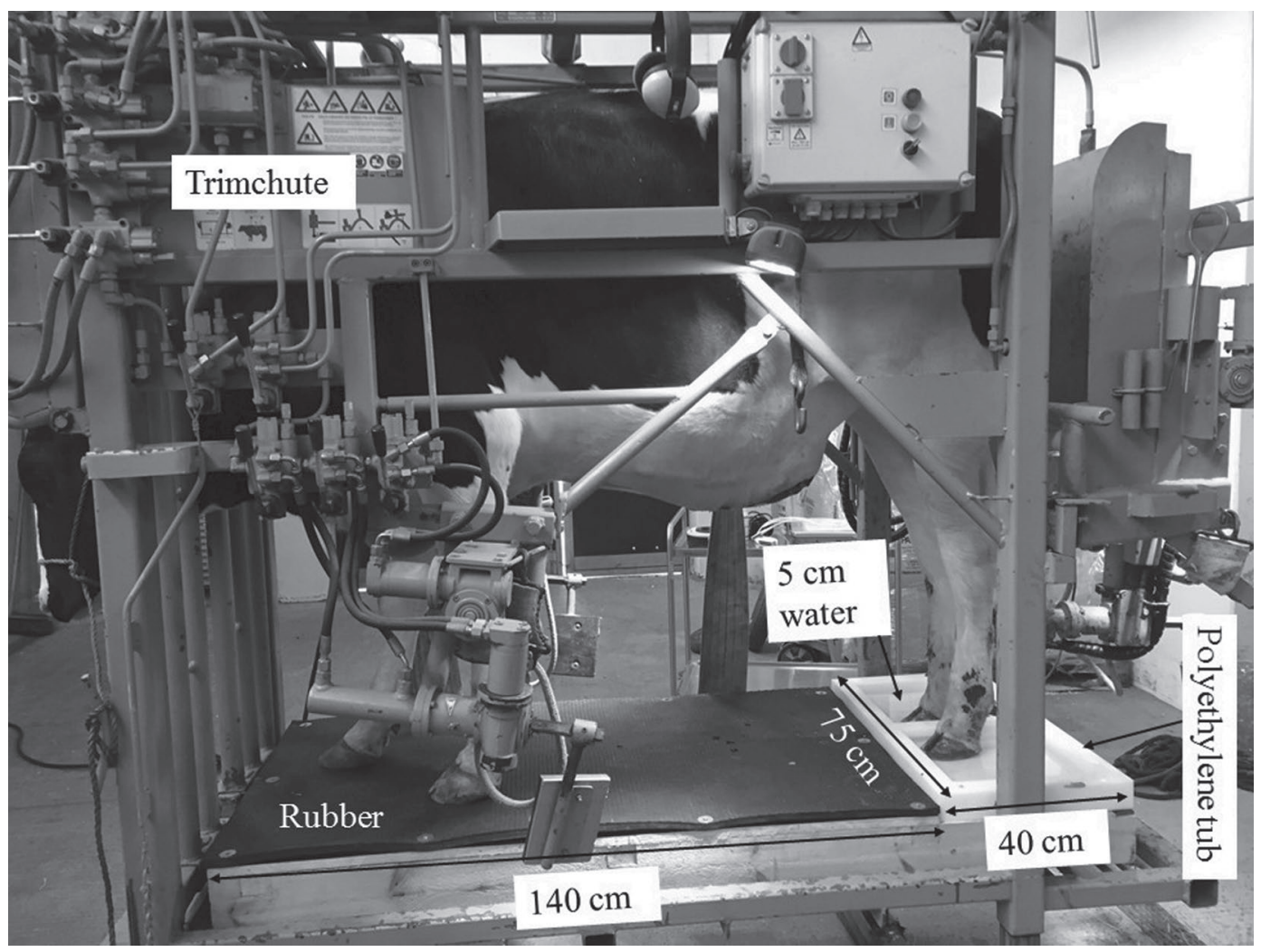

Figure 3. A Holstein heifer held in a stand-up trimming chute while standing on a platform. The hind claws are in a tub made of polyethylene and covered with $5 \mathrm{~cm}$ of water, and the front claws are on a rubber-covered platform. The dimensions of the tub are length, $40 \mathrm{~cm}$; width, 75 $\mathrm{cm}$; height, $6 \mathrm{~cm}$; and the thickness of the bottom, $10 \mathrm{~mm}$. 
Following this, the video loops were evaluated to identify the shortest distance between the sole horn and the third phalanx. Distance was measured using the software on the GE Logiq e.

The cows in the study did not experience any invasive examination methods and were only in the trimming chute for a short period ( $5 \mathrm{~min}$ ). Therefore, ethical approval of this part of the study was not needed under Danish standards.

\section{Statistical Analyses}

The measurements from the slaughterhouse feet were illustrated graphically using the ggplot2 package in $\mathrm{R}$ (R Core Team, 2014), with soft tissue thickness or sole thickness recorded using ultrasonography as outcomes plotted as a function of the soft tissue thickness or sole horn thickness recorded using a digital caliper on the transected claw. The latter method was considered to be the gold standard.

The hypothesis concerning the relationship between the measurements of soft tissue and sole horn thickness, made by the 3 methods at the 2 different sites of the sole horn, was assessed by calculating the Pearson correlation coefficient between the measurements in $\mathrm{R}$ (cor.test). The mean of the 3 direct scans at each site was paired with the mean of the 3 indirect scans at the same sites. The 3 direct and indirect scans were individually paired with the anatomical measurement, which was recorded using the digital caliper. Correlations were categorized for interpretation as follows: strong: $\mathrm{r}>0.7$, moderate: $0.7 \geq \mathrm{r}>0.5$, weak: 0.5 $\geq \mathrm{r}>0.3$, and no correlation: $0.3 \geq \mathrm{r}>0$ (Hinkle et al., 2003). To test if a significant difference was present between the anatomical measurements and each of the 2 ultrasonographical approaches, we used paired Student's $t$-tests in R (t.test)

Agreement between the mean of the 3 repeated measurements from the 2 different ultrasonographic methods of estimating soft tissue and sole thickness was evaluated using the limits-of-agreement method in R (Bland and Altman 1986). Plots were created using the "bland.altman.stats" function in the ggplot2 package and the limit of agreement was calculated with the "BlandAltman" function in the BlandAltmanLeh package. Before creating the plots, histograms were used to visually evaluate whether there was a normal distribution between measurements.

To assess the precision of the 2 different ultrasound approaches, correlations and repeatability between the first, second, and third measurements of the soft tissue and sole thickness were calculated. Repeatability was assessed using the limits-of-agreement method by calculating the mean difference and the coefficient of repeatability, defined as $1.96 \times$ standard deviation (Bland and Altman, 1986).

Linear relationships between recordings of the soft tissue from the claws of living animals were modeled using the $\mathrm{lm}$ function in $\mathrm{R}$, where the measurements of the weight-bearing claws were used as the outcome variable, and measurements of the lifted claws were used as the primary predictors. Due to the small sample size, correlations between the soft tissue thickness and the sole thickness measured on lifted and weight-bearing claws were calculated using Spearman's correlation in $\mathrm{R}$ (cor.test, method $=\mathrm{s}$ ) and the $95 \%$ confidence interval of the Spearman's correlation were calculated by using bootstrapping with 1,000 iterations using the "spearman.ci" in R.

\section{RESULTS}

\section{Method Development}

We developed a method as shown in Figures 1 and 3 and assessed the weight-carrying capacity of the tub with 10 individual cows weighing between 500 and 700 $\mathrm{kg}$. The tub did not break under the weight of any of the cows. The cows did not show any unexpected unwillingness to enter the stand-up chute with the platform, but to facilitate the process, we constructed a small ramp with rubber surface.

\section{Slaughterhouse Feet}

We examined 104 claws in 2 sites, 3 times by direct ultrasonography through the sole horn and 3 times by indirect ultrasonography through the polyethylene plate. In total, this was 1,248 ultrasonographical examinations on 52 feet. Mean values of the soft tissue and sole horn thickness at the 2 sites as measured using the different methods are presented in Table 1. The means of the ultrasound approaches were calculated as mean of the 3 repeated examinations. Graphical presentations of the data are shown in Figures 4 and 5.

Correlations between measurements obtained by the different methods are presented in Table 2. Weak to moderate correlation ( site $1: \mathrm{r}=0.35$; and site $2: \mathrm{r}=$ 0.60) was present between the anatomical soft tissue thickness and measurements from the direct ultrasonographical approach. No correlation was observed between the soft tissue measurements of from the indirect ultrasonographic approach and the anatomical measurements at site $1(\mathrm{r}=0.26)$, and at site 2 the correlation was weak $(r=0.38)$. The measurements from the direct ultrasonography were generally smaller than 


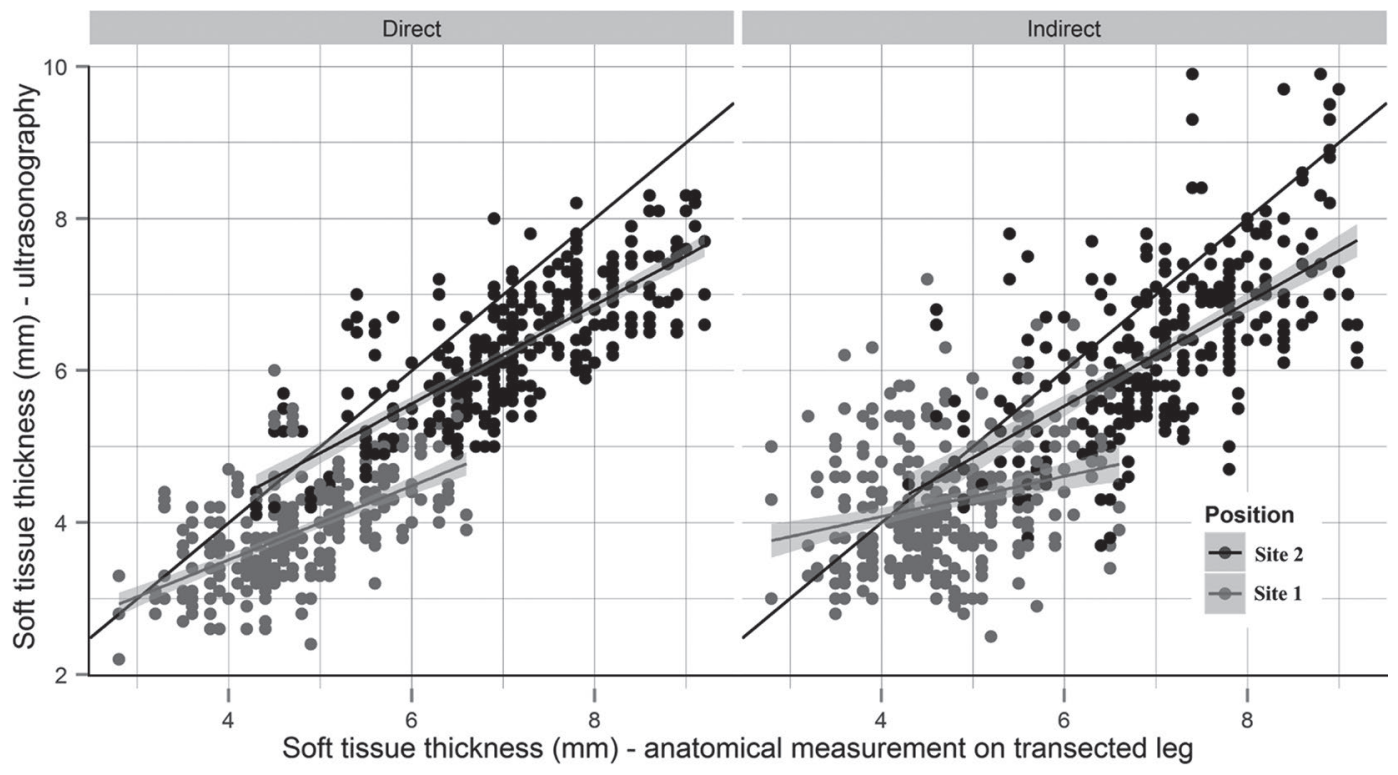

Figure 4. Soft tissue thickness measured by ultrasonography plotted against the anatomical soft tissue thickness measured using a digital caliper on a transected claw at 2 different sites (1 and 2). "Direct" scan is on the left, and "indirect" through a 10-mm-thick polyethylene plate is on the right. The gray shades of the graphs define the $95 \%$ CI.

the anatomical measurements at the same spots (site 1: $-0.8 \mathrm{~mm}$ and site $2:-0.4 \mathrm{~mm})$. This was also the case for indirect ultrasonographical measurements, where the mean difference from the anatomical measurements was $-0.4 \mathrm{~mm}$ at site 1 and $-0.8 \mathrm{~mm}$ at site 2 . These differences between anatomical and ultrasonographical measures was significant for both methods at both sites $(P<0.001)$.

However, there was strong correlation between the soft tissue thickness examined by direct and indirect ultrasound at site 1 (Pearson's $\mathrm{r}=0.66)$ and site $2(\mathrm{r}$ $=0.82$ ). Measurements of the sole horn thickness were generally more similar when comparing the different methods with correlations ranging from moderate to strong. The strongest correlations were seen between the 2 ultrasound approaches, with $\mathrm{r}=0.91$ at site 1 and $\mathrm{r}=0.89$ at site 2 .

The means of both soft tissue and sole thickness measurements using direct and indirect ultrasonography at the 2 sites are plotted against the difference between these 2 measures using limits-of-agreement plots (Figure 6). The plots show only a small difference between the methods, but a considerable variation was observed in the mean difference in soft tissue thickness at site 1 [difference $=-0.42 \mathrm{~mm}, 95 \% \mathrm{CI}(-1.50 ; 0.66 \mathrm{~mm})]$ and at site 2 [difference $=-0.003 \mathrm{~mm}, 95 \%$ CI $(-1.24 ; 1.22$

Table 1. Mean thickness of soft tissue and sole horn as measured using 3 different methods in the plantar part of the sole and at the apex of the sole horn of 52 slaughterhouse feet

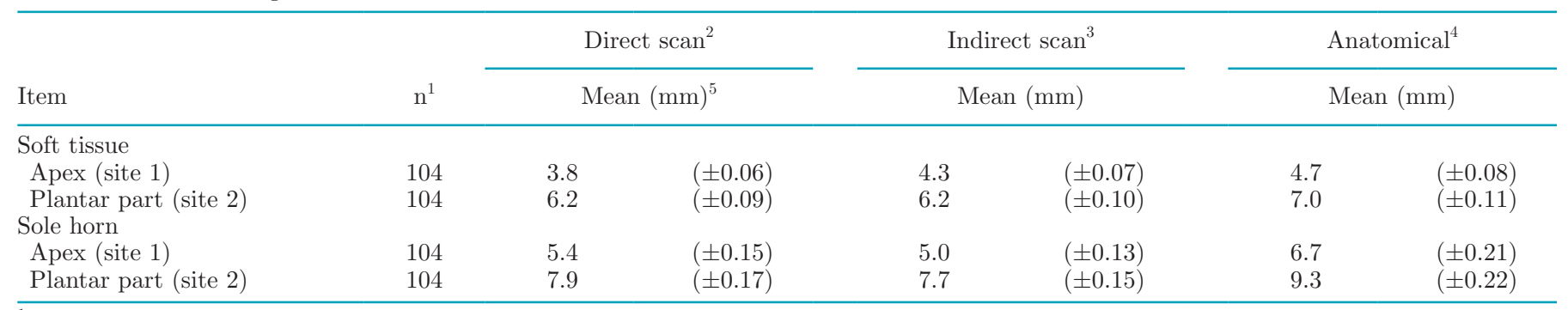

${ }^{1}$ Number of claws. Two claws on each foot.

${ }^{2}$ Ultrasound examination directly through the sole horn.

${ }^{3}$ Ultrasound examination through the polyethylene plate and sole horn.

${ }^{4}$ Measurements made with a digital sliding caliper on a transected claw.

${ }^{5}$ Mean of $3 \times 104$ measurements made at the site with the specific method. Standard error is displayed in parentheses. 


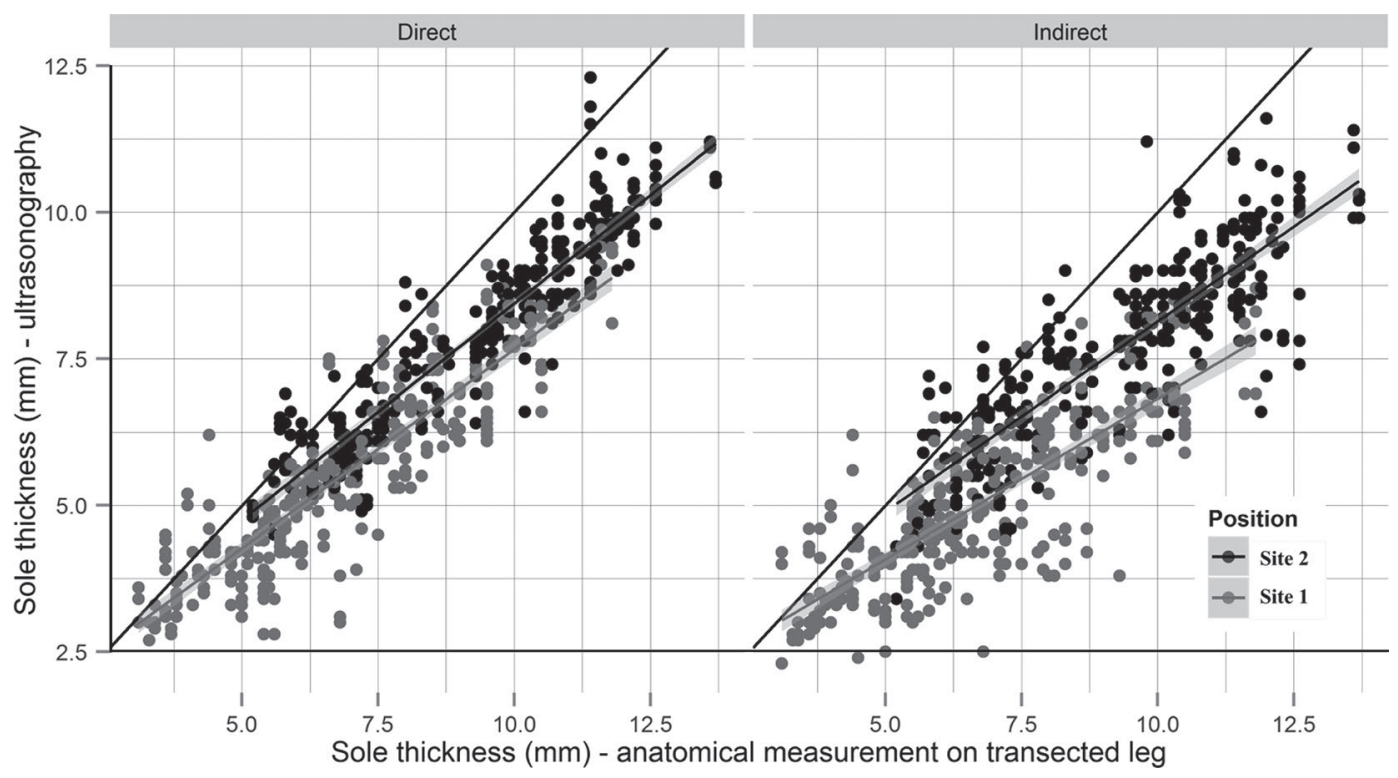

Figure 5. Sole thickness measured by ultrasonography plotted against the anatomical sole thickness measured using a digital caliper on a transected claw at 2 different sites (1 and 2) and using 2 different methods: "direct" scan (left) and "indirect" scan through a 10-mm polyethylene plate (right). The gray shades of the graphs define the $95 \%$ CI.

$\mathrm{mm})]$, as well as in the sole horn thickness measurements [site 1: difference $=0.41 \mathrm{~mm}, 95 \%$ CI $(-0.84$; $1.66)$ and site 2 : difference $=0.24 \mathrm{~mm}, 95 \%$ CI $(-0.99$; $1.47 \mathrm{~mm})]$.

The accuracy of the 2 methods was calculated as correlation and repeatability coefficients of the repeated measures derived using the same method on the randomized claws. The direct approach showed a strong correlation $(r \geq 0.95)$ between measurements of the soft tissue, with a coefficient of repeatability between \pm 0.74 and $\pm 0.88 \mathrm{~mm}$. Likewise, the indirect method showed a strong correlation $(r \geq 0.81)$ between the repeated soft tissue measurements, but a large coefficient of repeatability between \pm 1.66 and $\pm 1.71 \mathrm{~mm}$.

Strong correlations $(\mathrm{r}=0.97)$ and $(\mathrm{r} \geq 0.88)$ were also found between the repeated measurements of the

Table 2. Pearson correlation (correlation) coefficients (Spearman's for live cows) and mean difference (difference) with $95 \%$ CI in recordings based on a Bland-Altman analysis of the different methods of measuring soft tissue and sole horn thickness at the 2 sites (sites 1 and 2)

\begin{tabular}{llr}
\hline Comparison & \multicolumn{1}{c}{$\begin{array}{c}\text { Correlation, r } \\
(95 \% \mathrm{CI})\end{array}$} & $\begin{array}{c}\text { Difference, mm } \\
(95 \% \mathrm{CI})\end{array}$ \\
\hline Soft tissue thickness & $0.60(0.52 ; 0.66)$ & $-0.8(-2.2 ; 0.5)$ \\
Direct ultrasonographical vs. anatomical, site 1 & $0.35(0.25 ; 0.44)$ & $-0.4(-2.4 ; 1.6)$ \\
Direct ultrasonographical vs. anatomical, site 2 & $0.26(0.15 ; 0.36)$ & $-0.4(-2.4 ; 1.6)$ \\
Indirect ultrasonographical vs. anatomical, site 1 & $0.38(0.28 ; 0.47)$ & $-0.8(-2.7 ; 1.1)$ \\
Indirect ultrasonographical vs. anatomical, site 2 & $0.66(0.54 ; 0.76)$ & $-0.4(-1.5 ; 0.6)$ \\
Indirect vs. direct, site 1 & $0.80(0.72 ; 0.86)$ & $0.0(-1.2 ; 1.2)$ \\
Indirect vs. direct, site 2 & $0.48^{1}(0.18 ; 0.71)$ & $-0.5(-1.5 ; 0.6)$ \\
Indirect vs. direct, site 1, weight-bearing legs & $0.05^{1}(-0.24 ; 0.35)$ & $-1.0(-2.5 ; 0.5)$ \\
Indirect vs. direct, site 2, weight-bearing legs & & \\
Sole thickness & $0.89(0.86 ; 0.91)$ & $-1.3(-3.2 ; 0.7)$ \\
Direct ultrasonographical vs. anatomical, site 1 & $0.70(0.64 ; 0.75)$ & $-1.3(-3.1 ; 0.3)$ \\
Direct ultrasonographical vs. anatomical, site 2 & $0.82(0.77 ; 0.85)$ & $-1.7(-4.2 ; 0.8)$ \\
Indirect ultrasonographical vs. anatomical, site 1 & $0.66(0.59 ; 0.72)$ & $-1.6(-3.9 ; 0.7)$ \\
Indirect ultrasonographical vs. anatomical, site 2 & $0.89(0.87 ; 0.91)$ & $-0.4(-2.1 ; 1.3)$ \\
Indirect vs. direct, site 1 & $0.91(0.89 ; 0.93)$ & $-0.2(-2.0 ; 1.5)$ \\
Indirect vs. direct, site 2 & $0.31^{1}(-0.04 ; 0.59)$ & $0.5(-2.4 ; 3.3)$ \\
Indirect vs. direct, site 1, weight-bearing legs & $0.70^{1}(0.43 ; 0.86)$ & $1.1(-2.0 ; 4.2)$ \\
Indirect vs. direct, site 2, weight-bearing legs & & \\
\hline
\end{tabular}

${ }^{1}$ Spearman's correlation. 

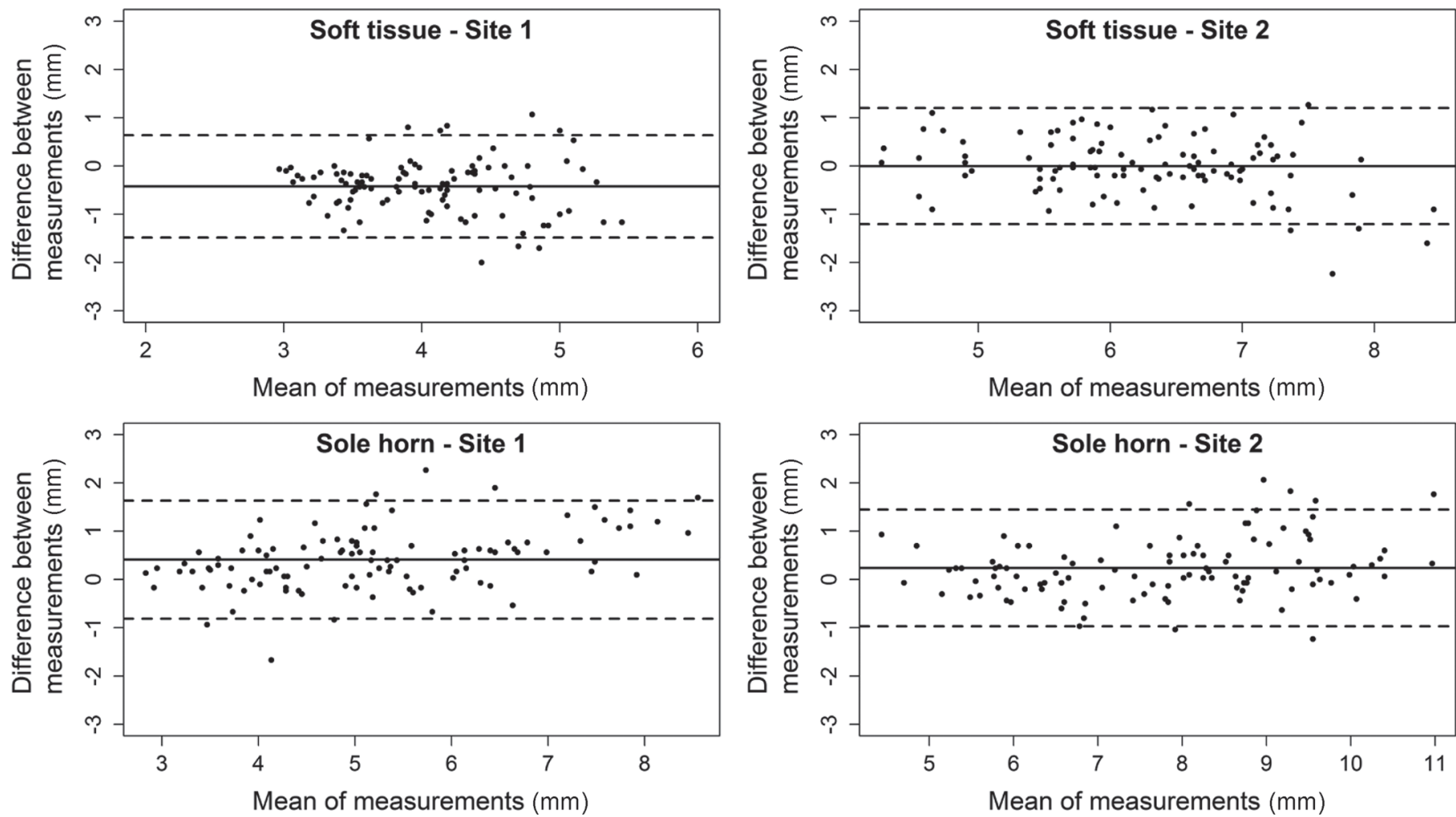

Figure 6. Measurements of soft tissue and sole horn thickness using direct and indirect ultrasonography at site 1 and 2 , plotted as the difference between the 2 measurements as a function of the mean of the 2 measurements. The thick solid line is the mean difference between the 2 measurements, and the 2 dashed lines are the $95 \%$ limits of agreement.

sole horn thickness with the direct and indirect methods, respectively. Coefficient of repeatability when measuring sole horn thickness was between \pm 0.91 and $\pm 1.05 \mathrm{~mm}$ with the direct method and between \pm 1.75 and $\pm 1.91 \mathrm{~mm}$ for the indirect method.

\section{Live Cows}

We made 16 examinations for each of the 10 cows, using both methods at 2 sites on each of the 2 claws from the hind legs. The thickness of the sole horn and soft tissue that we measured using the different methods at the different sites is presented in Table 3, and the correlation between soft tissue measurements using the different methods is illustrated in Figure 7. The soft tissue thickness that we recorded on the weight-bearing claws was only weakly correlated with the thickness on lifted legs at site 1 [Spearman's $r=0.48(0.18 ; 0.71)]$ and not correlated at site 2 [Spearman's $\mathrm{r}=0.05(-0.24 ; 0.35)$ ]. In terms of the sole horn thickness, a good correlation was only observed between the recording from the weight-bearing and non-weight-bearing claws at site 2 with a Spearman's correlation coefficient of $\mathrm{r}=0.70$ $(0.43 ; 0.86$; Table 2$)$.

Table 3. Measurements of soft tissue and sole horn thickness scanned on weight-bearing and non-weight-bearing claws from 10 live cows

\begin{tabular}{|c|c|c|c|c|c|c|c|c|c|}
\hline \multirow[b]{2}{*}{ Claw } & \multirow[b]{2}{*}{$\mathrm{n}$} & \multicolumn{2}{|c|}{$\begin{array}{c}\text { Soft tissue, } \\
\text { non-weight-bearing }\end{array}$} & \multicolumn{2}{|c|}{$\begin{array}{l}\text { Soft tissue, } \\
\text { weight-bearing }\end{array}$} & \multicolumn{2}{|c|}{$\begin{array}{c}\text { Sole horn, } \\
\text { non-weight-bearing }\end{array}$} & \multicolumn{2}{|c|}{$\begin{array}{c}\text { Sole horn, } \\
\text { weight-bearing }\end{array}$} \\
\hline & & Mean (mm) & $\mathrm{SD}$ & Mean (mm) & $\mathrm{SD}$ & Mean (mm) & $\mathrm{SD}$ & Mean (mm) & $\mathrm{SD}$ \\
\hline Apex (site 1) & 20 & 4.0 & $(0.7)$ & 3.4 & $(0.4)$ & 5.6 & $(1.5)$ & 6.2 & $(1.2)$ \\
\hline Plantar part (site 2) & 20 & 4.7 & $(0.6)$ & 3.6 & $(0.3)$ & 7.8 & $(1.6)$ & 9.2 & $(2.2)$ \\
\hline \multicolumn{10}{|l|}{ Medial } \\
\hline
\end{tabular}




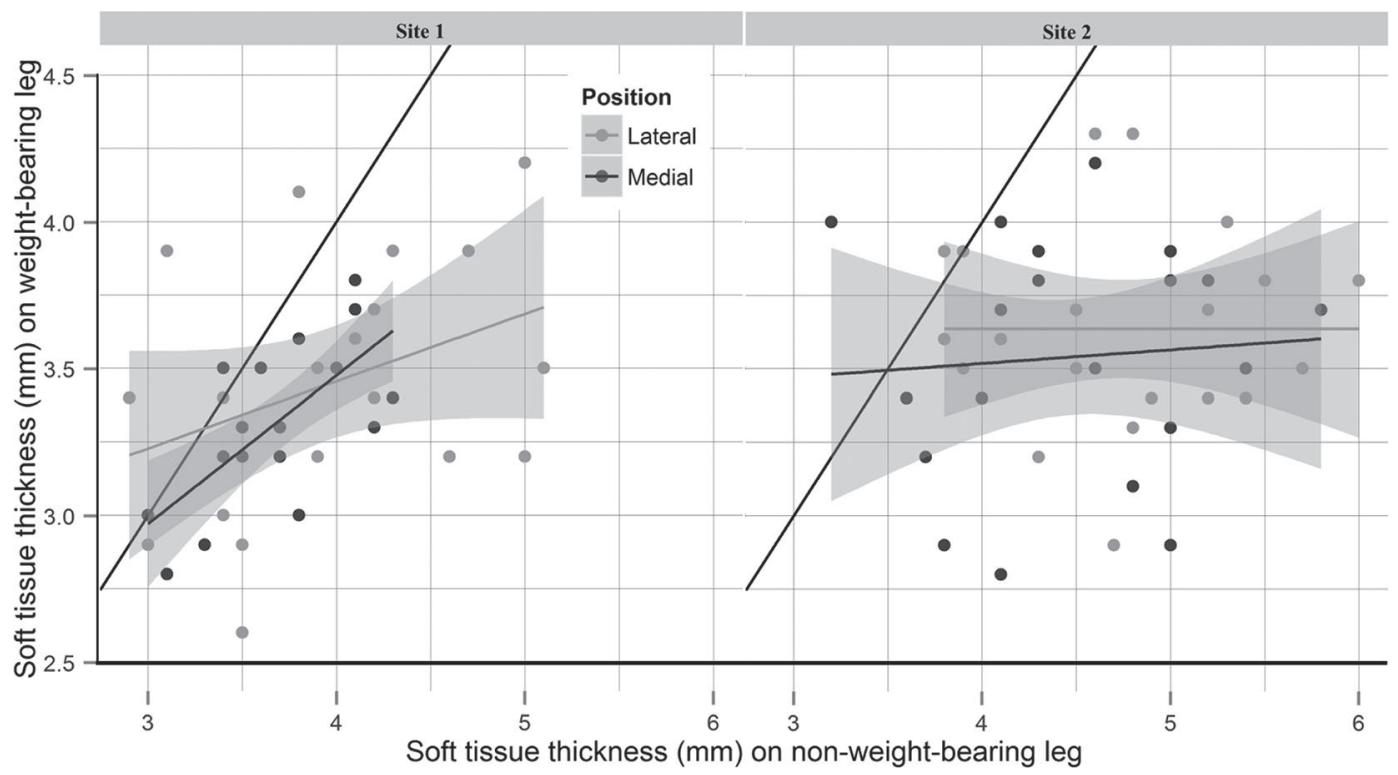

Figure 7. Ultrasonographical measurement of the soft tissue thickness on a lifted leg (x-axis) versus the soft tissue thickness on a weightbearing leg (y-axis) at site 1 (left) and site 2 (right). On both graphs, the gray shades define the 95\% CI. The straight black line without a shade illustrates a correlation of $\mathrm{r}=1$.

\section{DISCUSSION}

\section{Slaughterhouse Feet}

To our knowledge, this was the first study to describe the distance between the distal part of the bovine third phalanx and the sole horn on a weight-bearing claw, measured using ultrasound through the sole horn and a polyethylene plate. There was little difference between the direct and indirect recordings of the soft tissue on slaughterhouse claws (Figures 4 and 6 and Table 2), and the correlation was strong especially at site 2 .

However, comparison of measurements from the 2 ultrasonographic approaches with the anatomical measurements made on transected claws only showed a weak correlation. Both methods were significantly lower than the anatomical measurements, and it seems that the difference increases with increasing thickness of the measured tissue (Figures 4 and 5). When comparing measurements of the sole horn thickness, the correlations were stronger, but the anatomical measurements were still higher than the 2 ultrasound approaches.

The images from the indirect scans were affected by a distortion that caused structures to appear smaller on the image than in reality. The bottom of the tub was $10 \mathrm{~mm}$ thick, yet it appeared to be $7.5 \mathrm{~mm}$ on the images. This may explain why the anatomical measurements of soft tissue thickness taken with a digital caliper were generally higher than the measurements from ultrasound images. Kofler et al. (1999) also reported thinner soft tissue measured with ultrasound compared with anatomical measurements. They explained this discrepancy as the expansion of the soft tissue when the fresh claw was transected. We transected the claws and took the anatomical measurements while they were frozen and did not experience any expansion of the soft tissue either during or after the transection. Furthermore, based on preliminary test transections, we found it easier to identify the inner margin of the sole horn on a frozen transected claw than on a nonfrozen claw. Laven et al. (2012) also found that ultrasound measurements were lower than corresponding anatomical measurements. They took anatomical measurements from frozen claws and speculated that the expansion of soft tissue during the freezing process could explain some of the difference. Because the same differences between ultrasound and anatomical measurements have been described regardless of whether the claws were frozen, we suggest that the discrepancy is due to a distortion of ultrasound images when the waves transferred through the sole horn. This effect was therefore not fully attributable to the polyethylene plate bending the waves, distorting the images and appearing smaller on the image, as this can also occur when the waves are transferred through the sole horn by direct scanning.

It was relatively easy to place the transducer in the same site on the sole at every measurement during direct scanning, as described in other studies (van 
Amstel et al., 2004; Laven et al., 2012; Toholj et al., 2014). The transection was made through burn marks created at the site of the last direct scan. Consequently, there should be relatively good correspondence between measurements from direct scanning and anatomical measurements. However, it was not possible to visualize the sole horn while scanning through the polyethylene plate, and the transducer was instead positioned based on the image findings. Our fixed points for measurements were the shortest distances between the inside margin of the sole horn and the tuberculum flexorum and apex of the distal phalanx. The 2 different methods of identifying the sites could explain some of the reduced correlation between direct and indirect scans and anatomical measurements. Likewise, it could be a source to the variation that is seen as a decreased repeatability of the indirect method compared with the direct method.

It was our intention to place the transducer perpendicular to the surface of the polyethylene plate and to measure the shortest distance to the structures above the plate and the sole horn. However, obtaining the optimal image sometimes required the transducer to be rotated along its longitudinal axis, as described by van Amstel et al. (2004). This might have increased the distance between the transducer and the structures we wanted to measure, thus influencing the measurements on the images.

Because the intention with the indirect method was to make repeated measurements of the soft tissue over time, we found it relevant to assess the precision of the 2 methods by making repeated scans of the same claws. With the direct approach, it was easier to place the transducer at the same spot of the sole horn every time, resulting in a higher correlation and a lower coefficient of repeatability between the repeated measurements compared with the indirect method. When comparing measurements of the sole horn, the results were similar. The indirect method was less accurate than the direct method. This must be taken into consideration when interpreting repeated measurements of soft tissue and sole horn in longitudinal studies.

\section{Live Cows}

Correlations between measurements from weightbearing legs on live cows were weak, with the exception of the sole thickness recorded at site 2 (Table 2). This may indicate a major difference in the measurements made indirectly on weight-bearing and directly on non-weight-bearing claws, since there appears to be a good correlation between the methods for slaughterhouse claws, but not for the live cows. We suggest that the difference is a consequence of weight-bearing, and that method plays only a minor role. Otherwise, a weak correlation should also have been identified for the slaughterhouse claws. However, we must still take into consideration that the sample size of live cows was rather small $(\mathrm{n}=10)$ and the difference of the soft tissue thickness in weight-bearing versus non-weightbearing should be interpreted with caution.

Several factors might have influence on how big of an effect the weight-bearing has on compression of the soft tissue. The weight of the cow could play a major role and we might see a greater difference between weightbearing and non-weight-bearing on a heavy $800-\mathrm{kg}$ Holstein cow compared with a small $500-\mathrm{kg}$ cow of the same breed. Body condition has been proved to play a role on the thickness of the soft tissue (Bicalho et al., 2009; Newsome et al., 2017) resulting in thinner soft tissue on cows with a low body condition. Thicker soft tissue might allow greater absolute compression when the claw is loaded, but the compression of a thinner soft tissue layer on a cow with a low body condition might be more crucial due to the risk of damage of the underlying horn-producing tissue. It has been suggested that the composition of the fat tissue differs between young and older animals (Räber et al., 2006). This is thought to play a significant role in the load capacity and elastic properties of the digital cushion and age of the cow could be a factor affecting the thickness of the soft tissue of weight-bearing claw. Around the time of calving, physiological and metabolic changes seem to make the suspensory and supportive apparatus in the claw softer and weaker (Tarlton et al., 2002). Stage of lactation is consequently likely to affect the thickness of the soft tissue in the weight-bearing claw.

\section{Method Evaluation}

Regardless of the scanning method, the distal part of the third phalanx was visualized as a thick curved hyperechoic line (Figure 2). The inner margin of the sole horn appeared as a thin hyperechoic line, which in most cases was relatively easy to identify. However, in some images from the indirect method, the hyperechoic line from the inside sole horn margin was interrupted or blurred. In other cases, it was difficult to identify the margin because of vertical linear artifacts, which we believe originated from reflections when the waves moved from polyethylene to water or sole horn (Figure 2). In particular, we experienced problems in clearly identifying the inside margin of the sole horn at site 1 . Kofler et al. (1999) and Laven et al. (2010) also described problems in identifying the inside margin of the sole horn in some claws. These disturbances in the images made it harder to take exact measurements. When the inside margin of the sole horn was difficult to identify, 
we estimated its position by extending the echoic line from elsewhere in the image, which could account for some of the variation.

In general, the image quality from the indirect scans seemed to be better on live cows than on the feet from slaughterhouses. This may be due to the weight from the cow increasing the contact between the polyethylene plate and the sole horn, thus reducing artifacts and making it easier to identify the inner sole horn margin.

We did not trim the claws of the live cows before the examinations as described in other studies (Kofler et al., 1999; van Amstel et al., 2003). In most cases, we found that it was possible to obtain an acceptable ultrasound image of the nontrimmed claws on the polyethylene plate, provided they were relatively clean and not overgrown. Disadvantages of ultrasonographical examinations through the polyethylene plate included reduced image quality and a more time-consuming examination. When examining the claws of live cows through the polyethylene, it was difficult to identify the external margin of the horn sole because it appeared blurred next to the sharp edge of the plate. We cannot be certain that this did not affect the measurements of sole horn thickness, especially at site 1 , where the concavity of the sole horn in the untrimmed claw reduced the contact surface between the polyethylene plate and the sole horn. In contrast there seemed to be a better contact at the plantar part of the sole, which made it easier to identify the external margin of the sole horn, resulting in a higher correlation between sole horn thickness measurements made on weight-bearing and non-weight-bearing claws.

We investigated different types of ultrasound machines to assess whether they could provide an image when scanning through sole horn and polyethylene. We recommend that the ultrasound device should be of high quality and with a high resolution to provide an acceptable image when scanning through the polyethylene plate. We also assessed various kinds of plastic and found that the 10-mm-thick polyethylene plate was strong enough to support the weight of the cows, whereas thicker plates and plexiglass are likely to create too many artifacts.

In conclusion, we found that indirect ultrasonographical scanning through a polyethylene plate provided an alternative method to the direct ultrasonographical approach on making measurements of the soft tissue and sole horn of the bovine claw. However, the indirect method was less precise and more time consuming and this must be taken in to consideration when choosing the method. The correlation between weight-bearing and lifted legs was weak, probably because weightbearing has a major effect on the soft tissue thickness. With numerous factors that can possibly affect the thickness of the digital cushion, we suggest that future studies on soft tissue are performed on weight-bearing legs, whereas studies on sole horn thickness still should be done using a direct ultrasound approach.

\section{ACKNOWLEDGMENTS}

We thank the slaughterhouse Mogens Nielsen Kreaturslagteri A/S (Herlufmagle, Denmark) for providing the feet. We also thank the staff of the Large Animal Teaching Hospital at the University of Copenhagen (Taastrup, Denmark) for helping with the handling of cows and feet. Our thanks also go to VetFond (Lögumkloster, Denmark) for funding the construction of the polyethylene tub.

\section{REFERENCES}

Bicalho, R. C., V. S. Machado, and L. S. Caixeta. 2009. Lameness in dairy cattle: A debilitating disease or a disease of debilitated cattle? A cross-sectional study of lameness prevalence and thickness of the digital cushion. J. Dairy Sci. 92:3175-3184. https://doi .org/10.3168/jds.2008-1827.

Bicalho, R. C., F. Vokey, H. N. Erb, and C. L. Guard. 2007. Visual locomotion scoring in the first seventy days in milk: Impact on pregnancy and survival. J. Dairy Sci. 90:4586-4591. https://doi .org/10.3168/jds.2007-0297.

Bland, J. M., and D. G. Altman. 1986. Statistical methods for assessing agreement between two methods of clinical measurement. Lancet 1:307-310. https://doi.org/10.1016/S0140-6736(86)90837-8.

Bruijnis, M. R., H. Hogeveen, and E. N. Stassen. 2010. Assessing economic consequences of foot disorders in dairy cattle using a dynamic stochastic simulation model. J. Dairy Sci. 93:2419-2432. https://doi.org/10.3168/jds.2009-2721.

Ettema, J. F., N. Capion, and A. E. Hill. 2007. The association of hoof lesions at claw trimming with test-day milk yield in Danish Holsteins. Prev. Vet. Med. 79:224-243. https://doi.org/10.1016/j .prevetmed.2006.12.007.

Fritzbøger, E., and H. H. Smedegaard. 1962. Klovens Beskaering. Pages 148-155 in Kvaegets Klovpleje. 2nd ed. Carl Fr.Mortensen. Veterinaermedicinsk bog- og instrumenthandel, Copenhagen, Denmark.

Hendee, W. R., and E. R. Ritenour. 2003. Ultrasound Waves. Pages 303-316 in Medical Imaging Physics. 4th ed. John Wiley \& Sons Inc., New York, NY.

Hinkle, D. E., W. Wiersma, and S. G. Jurs. 2003. Applied Statistics for the Behavioral Sciences. 5th ed. Houghton Mifflin, Boston, MA.

Klaas, I. C., T. Rousing, C. Fossing, J. Hindhede, and J. T. Sorensen. 2003. Is lameness a welfare problem in dairy farms with automatic milking systems? Anim. Welf. 12:599-604.

Kofler, J., P. Kubber, and W. Henninger. 1999. Ultrasonographic imaging and thickness measurement of the sole horn and the underlying soft tissue layer in bovine claws. Vet. J. 157:322-331. https:// doi.org/10.1053/tvjl.1998.0315.

Laven, L., J. Margerison, and R. Laven. 2010. Measurement of sole thickness and distance to distal phalanx using a portable ultrasound machine. Pages 240-242 in Proc. N. Z. Soc. Anim. Prod. Vol. 70. New Zealand Society of Animal Production, Palmerston North.

Laven, L. J., J. K. Margerison, and R. A. Laven. 2012. Validation of a portable ultrasound machine for estimating sole thickness in dairy cattle in New Zealand. N. Z. Vet. J. 60:123-128. https://doi.org/ 10.1080/00480169.2011.644215.

Lischer, C. J., P. Ossent, M. Raber, and H. Geyer. 2002. Suspensory structures and supporting tissues of the third phalanx of cows and 
their relevance to the development of typical sole ulcers (Rusterholz ulcers). Vet. Rec. 151:694-698.

Matteoli, S. 2011. Diagnosis of heel pad injuries. PhD Thesis. Department of Electrical Engineering, Technical University of Denmark, Kgs. Lyngby, Denmark.

Newsome, R. F., M. J. Green, N. J. Bell, N. J. Bollard, C. S. Mason, H. R. Whay, and J. N. Huxley. 2017. A prospective cohort study of digital cushion and corium thickness. Part 1: Associations with body condition, lesion incidence, and proximity to calving. J. Dairy Sci. 100:4745-4758. https://doi.org/10.3168/jds.2016-12012.

Räber, M., M. R. L. Scheeder, P. Ossent, C. J. Lischer, and H. Geyer. 2006. The content and composition of lipids in the digital cushion of the bovine claw with respect to age and location-A preliminary report. Vet. J. 172:173-177. https://doi.org/10.1016/j.tvjl.2005.03 .009 .

R Core Team. 2014. R: A language and environment for statistical computing. R Foundation for Statistical Computing, Vienna, Austria. http://www.R-project.org/.
Tarlton, J. F., D. E. Holah, K. M. Evans, S. Jones, G. R. Pearson, and A. J. F. Webster. 2002. Biomechanical and histopathological changes in the support structures of bovine hooves around the time of first calving. Vet. J. 163:196-204. https://doi.org/10.1053/tvjl .2001 .0651 .

Toholj, B., M. Cincovic, M. Stevancevic, J. Spasojevic, V. Ivetic, and A. Potkonjak. 2014. Evaluation of ultrasonography for measuring solar soft tissue thickness as a predictor of sole ulcer formation in Holstein-Friesian dairy cows. Vet. J. 199:290-294. https://doi.org/ 10.1016/j.tvjl.2013.11.005.

van Amstel, S. R., F. L. Palin, B. W. Rorhbach, and J. K. Shearer. 2003. Ultrasound measurement of sole horn thickness in trimmed claws of dairy cows. J. Am. Vet. Med. Assoc. 223:492-494. https:/ /doi.org/10.2460/javma.2003.223.492.

van Amstel, S. R., F. L. Palin, and J. K. Shearer. 2004. Measurement of the thickness of the corium and subcutaneous tissue of the hind claws of dairy cattle by ultrasound. Vet. Rec. 155:630-633. https:/ /doi.org/10.1136/vr.155.20.630 